\title{
Separation of organic liquid mixture by flexible nanofibrous membranes with precisely tunable wettability
}

\author{
Lanlan Hou ${ }^{1,4}$, Li Wang ${ }^{2,4}$, Nü Wang ${ }^{1,3}$, Fengyun Guo ${ }^{1}$, Jing Liu' ${ }^{1}$, Yuee Chen ${ }^{1}$, Jingchong Liu ${ }^{1}$, \\ Yong Zhao $^{1}$ and Lei Jiang ${ }^{2}$
}

Separation of liquid mixtures, especially organic liquid mixtures, is widely used in industrial processes but still faces challenges with respect to separation in a high-efficiency, low-energy mode. In this work, we report a flexible wettability-tunable nanofibrous membrane composed of a high-performance fluoro-polymer as the matrix and fluorosilane as a surface energy regulator that can be successfully applied in immiscible organic liquid mixture separation. The separation is achieved by tuning the surface energy of a membrane to a value between the surface tensions of two organic liquids. Moreover, for use in different mixed liquid systems, we programmatically designed nanofibrous membranes with the proper surface energy that could intercept the relatively high surface tension liquid and allow the low surface tension liquid to pass through. These membranes are expected to become a competitive candidate for complex organic chemical product separation, resource recycling, and environmental protection.

NPG Asia Materials (2016) 8, e334; doi:10.1038/am.2016.179; published online 2 December 2016

\section{INTRODUCTION}

Liquid mixtures of solvents or reactants are ubiquitously applied in processes in the petrochemical, textile printing, food and medical industries. These complex liquid mixtures often must be separated after reaction for the purpose of product purification, resource recycling or harmless discharge. ${ }^{1}$ Traditional liquid separation methods such as distillation and separation have exposed many drawbacks, including high-energy consumption, low flux and low efficiency, that dramatically increase the separation time and cost. ${ }^{2}$ Therefore, challenges remain for the development of separation processes of organic liquid mixtures that are efficient, allow high throughput and conserve energy. Among various separation approaches, the membrane separation technique has been extensively proven as a high throughput and energy-efficient choice..$^{3-5}$ Over the past decade, various membranes with special wettability properties have been successfully prepared and have exhibited excellent performance in oil/water separation. The mechanisms of membrane separation are based on exact opposite wettabilities toward oil and water, including superhydrophobic/superoleophilic membranes ${ }^{3,5-8}$ or superhydrophilic/superoleophobic membranes. ${ }^{9-15}$ For example, superhydrophobic/oleophilic membranes have been prepared from various materials, including metals, polymers or even clothes and filter papers, that could intercept water and allow oil to pass through. ${ }^{16-20}$ In addition, researchers have gained inspiration from oil-contaminantfree fish skin to fabricate oil-repellent hydrogel membranes that could separate oil from water. ${ }^{21,22}$ Although significant progress has been achieved for membrane-based oil/water separation in the last few years, development of separation membranes for organic liquids is still highly limited because organic liquids usually possess a relatively lower surface tension than water. The difficulty in separation of organic liquid mixtures has increased because it is more difficult to build a superoleophobic ${ }^{23-29}$ material than a superhydrophobic material. We recently proposed an oleophobicity-tunable $\mathrm{TiO}_{2}$ nanofibrous membrane prepared by electrospinning, calcination and a subsequent chemical modification method that achieved immiscible organic liquids separation. ${ }^{30}$ However, the multistep fabrication process, complex types of silanes and intrinsic brittleness of the inorganic materials largely restrict its practicability. Therefore, further investigations are required to prepare a flexible and easily obtained membrane for use in immiscible organic liquids separation. In this work, we report a flexible polymeric nanofibrous membrane with good tunable oleophobicity that is able to separate an immiscible organic liquid mixture in a highly efficient manner. The advantage of this method is that the wettability of the membrane can be simply but

\footnotetext{
${ }^{1}$ Laboratory of Bioinspired Smart Interfacial Science and Technology of the Ministry of Education, Beijing Key Laboratory of Bioinspired Energy Materials and Devices, School of Chemistry and Environment, Beihang University, Beijing, China; ${ }^{2}$ Beijing National Laboratory for Molecular Sciences (BNLMS), Key Laboratory of Organic Solids, Institute of Chemistry, Chinese Academy of Sciences, Beijing, China and ${ }^{3}$ Institute for Superconducting and Electronic Materials, University of Wollongong, North Wollongong, NSW, Australia ${ }^{4}$ These authors contributed equally to this work.

Correspondence: Dr N Wang or Professor Y Zhao, Laboratory of Bioinspired Smart Interfacial Science and Technology of the Ministry of Education, Beijing Key Laboratory of Bioinspired Energy Materials and Devices, School of Chemistry and Environment, Beihang University, Xueyuan Road No. 37, Beijing 100191, China.

E-mail: wangn@buaa.edu.cn or zhaoyong@buaa.edu.cn

Received 12 June 2016; revised 1 September 2016; accepted 18 September 2016
} 
precisely tuned according to the surface tension of the liquids, which are to be separated from each other. This approach offers a general solution for separation of multiphase organic liquid mixtures and is promising for extensive industrial and environmental domains.

\section{MATERIALS AND METHODS}

\section{Materials}

PVDF-HFP (poly(vinylidene fluoride-co-hexafluoropropylene), $\mathrm{Mw}=400$ 000, Sigma-Aldrich, Milwaukee, WI, USA), PFDTMS $(1 \mathrm{H}, 1 \mathrm{H}, 2 \mathrm{H}, 2 \mathrm{H}$-perfluorodecyltrimethoxysilane, TCI), acetone and N, N-dimethylacetamide (A.R., Beijing Chemical Works, Beijing, China).

\section{Fabrication of PVDF-HFP/PFDTMS composite membranes}

The PVDF-HFP/PFDTMS membranes were fabricated by co-dissolving PVDF-HFP and PFDTMS in a mixture of acetone and N, N-dimethylacetamide (DMAc) $(7: 3 \mathrm{w} / \mathrm{w})$ to form a homogeneous and transparent solution with 15 wt $\%$ PVDF-HFP. The weight ratios of PVDF-HFP to PFDTMS were adjusted to 30:1 (M-30/1), 15:1 (M-15/1), 10:1 (M-10/1) and 5:1 (M-5/1). The solution was electrospun under a working voltage of $18 \mathrm{kV}$ and at a receiving distance of $20 \mathrm{~cm}$. The as-fabricated membranes could be peeled from the aluminum foil substrates, and thus PVDF-HFP/PFDTMS composite separation membranes were obtained.

\section{Liquid mixture separation experiments}

The membrane was fixed via flange equipment. A glass tube with an inner diameter of $37 \mathrm{~mm}$ was connected on the top of the flange equipment. The organic liquid mixture was poured onto the PVDF-HFP/PFDTMS membrane, and the liquid with the lower surface tension permeated through the membrane spontaneously.

\section{Instruments and characterization}

Field emission scanning electron microscope (FE-SEM) images were collected using a JSM-7500F instrument, JEOL, Japan. The contact angle (CA) values were obtained on an OCA20 instrument (Data-Physics, Stuttgart, Germany) at room temperature. The CAs were measured in at least six different locations with a sample volume of $2 \mu \mathrm{l}$ to calculate the average value. The separation process videos were recorded on a Canon-500D digital camera (Canon, Tokyo, Japan). The mechanical properties were investigated on a tensile tester (Shimadzu, AGS-X $1 \mathrm{KN}$, Kyoto, Japan) with a stretching rate of $10 \mathrm{~mm} \mathrm{~min}{ }^{-1}$ and maximum load of $100 \mathrm{~N}$ at room temperature. The width of each membrane was $10 \mathrm{~mm}$ with a length of $10 \mathrm{~mm}$. The Fourier transform infrared spectra were analyzed on a microscope infrared spectrometer (Nicolet, iN10MX, Madison, WI, USA) and Fourier transform infrared spectrometer (Spectrum GX, PE, Waltham, MA, USA). The ultraviolet absorptions were tested on a UV-Vis-NIR spectrophotometer (Shimadzu, UV-3600) manufactured in Japan.

\section{RESULTS AND DISCUSSION}

The nanofibrous separation membrane was fabricated using the commercially available fluoro-containing polymer poly (vinylidene fluoride-co-hexafluoropropylene) (PVDF-HFP) ${ }^{31}$ via a simple electrospinning method ${ }^{32-35}$ in which $1 \mathrm{H}, 1 \mathrm{H}, 2 \mathrm{H}$, 2H-perfluorodecyltrimethoxysilane (PFDTMS) was doped as a regulator for tuning of the oleophobicity of the membrane. Figure 1 demonstrates the fabrication and separation process of the membrane. PVDF-HFP and PFDTMS were co-dissolved in N, N-dimethylacetamide (DMAc) and acetone to form a homogeneous solution and subsequently electrospun into a nanofibrous membrane. For a certain organic liquid mixture, the surface free energy of such a membrane could be facilely controlled to repel one organic liquid and become wetted by another liquid via tuning of the content of PFDTMS. In other words, this membrane allows pass-through of a relatively low surface tension wettable liquid and intercepts another high surface tension non-wettable liquid such that an organic liquid mixture could be separated. In this work, PVDF-HFP is used as a matrix for the
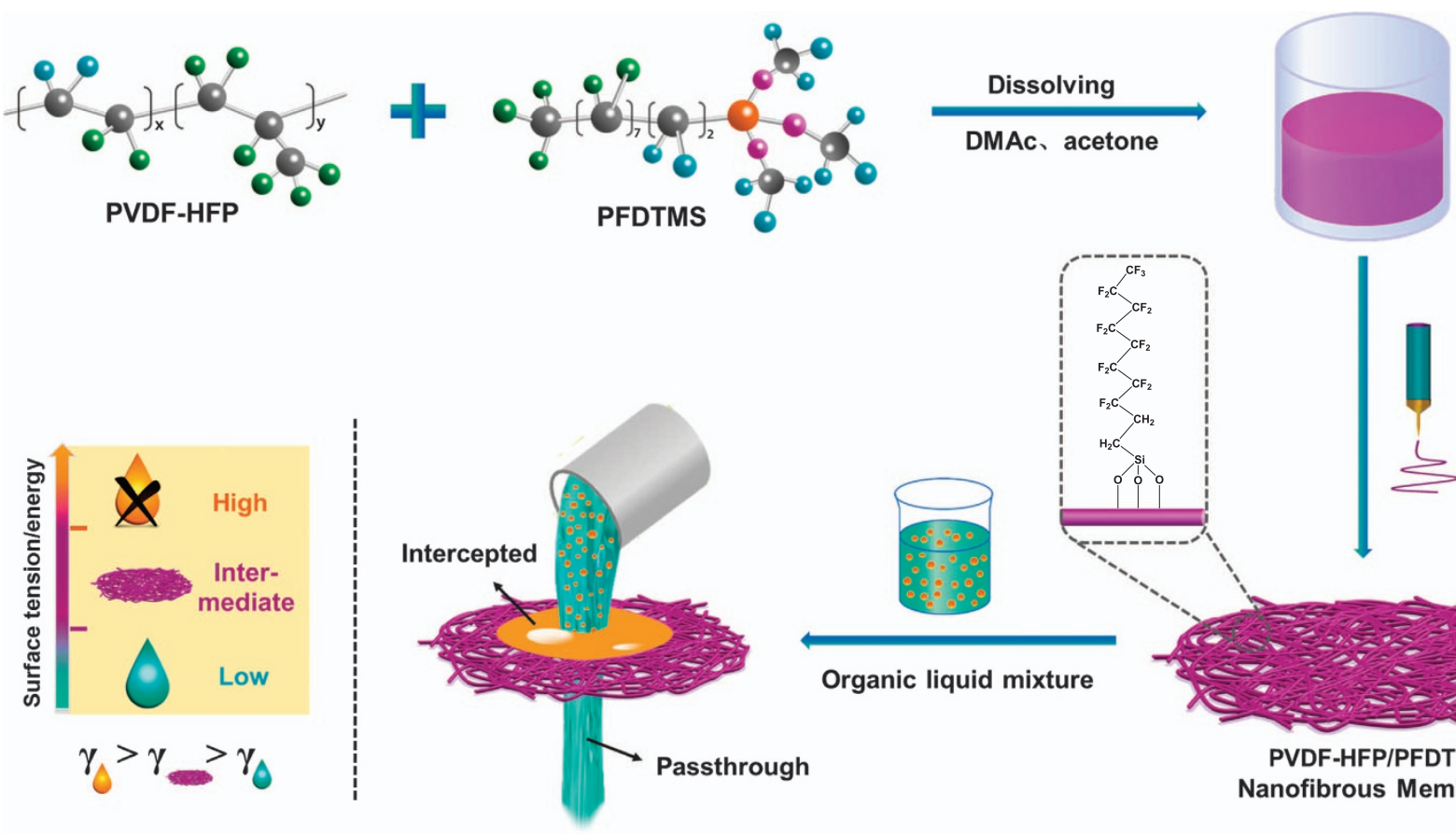

Organic liquid mixture

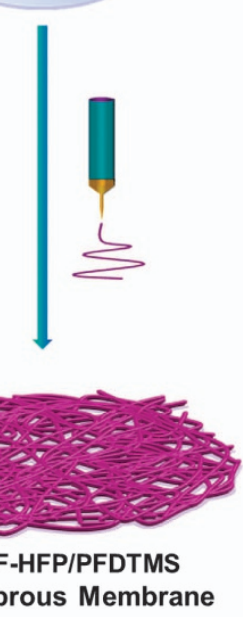

Figure 1 Schematic illustration of PVDF-HFP/PFDTMS nanofibrous separation membrane preparation. PVDF-HFP and PFDTMS are co-dissolved and electrospun into a nanofibrous membrane. The surface energy of the membrane is tuned by controlling the doping content of PFDTMS. If a membrane has a moderate surface energy that falls between the surface tensions of the two organic liquid phases, the higher surface tension liquid is intercepted by the membrane and the lower surface tension liquid passes through the membrane spontaneously to achieve separation. 
membrane due to its superior performance in terms of solvent resistance, chemical stability and mechanical properties. It is worth noting that PVDF-HFP itself is an intrinsic relatively low surface energy material with excellent hydrophobicity that can be electrospun into a superhydrophobic nanofibrous membrane with a water CA of $139.9 \pm 0.6^{\circ}$, but it is simultaneously superoleophilic for most organic liquids (Supplementary Figure S1). Such a superhydrophobic/ superoleophilic membrane could be used in oil/water separation (Supplementary Video 1 and Supplementary Figure S2), as previous works have demonstrated. ${ }^{3,12,18}$ However, this membrane could not be applied to separate low surface tension organic liquid mixtures (Supplementary Video 2), which means that the surface energy of pure PVDF-HFP is lower than that of water but higher than that of most of organic liquids. Therefore, to separate low surface tension organic liquids, it is necessary to further decrease the surface energy of the membrane to a suitable range that falls exactly in between the surface tension of the two organic liquids. In other words, such a membrane should be wettable for one liquid and non-wettable for another. On the basis of this principle, the membrane should exhibit a distinguishing effect that permits the wettable liquid to pass through and blocks another non-wettable liquid. The difficulty in achieving this goal lies in the fact that the surface tension differences between organic liquids are usually quite small, which presents a great challenge for material design. In this work, we show that PFDTMS, a long-chain silane with eight perfluoro carbons, can be used as a surface energy regulator of the PVDF-HFP membrane by simply controlling the doping content. Figure 2 shows the morphology of PFDTMS-doped PVDF-HFP nanofibrous membranes. In this work, pure PVDF-HFP membrane and four PVDF-HFP/PFDTMS composite membranes were fabricated using different weight ratios between the PVDF-HFP and the PFDTMS of 30:1, 15:1, 10:1 and 5:1 (denoted as M-30/1, M-15/1, M-10/1 and M-5/1, respectively). The diameters of the pure PVDF-HFP fibers are in the range of $120-540 \mathrm{~nm}$, with an average diameter of $299 \pm 7 \mathrm{~nm}$. The average diameters of the four fibers from M-30/1 to $M-5 / 1$ are $517 \pm 11 \mathrm{~nm}, 402 \pm 11 \mathrm{~nm}, 538 \pm 8 \mathrm{~nm}$ and $547 \pm 10 \mathrm{~nm}$, respectively (Figures $2 \mathrm{a}-\mathrm{f}$ ). The nanofibers interweave to form a dense porous membrane, and no defects such as pores or wrinkles are observed on the nanofibers under higher magnification, as shown in the inset of Figures $2 \mathrm{~b}-\mathrm{f}$. Fourier transform infrared spectroscopy (Supplementary Figure S3) confirms that the PFDTMS was successfully doped into the composite fiber membranes. A slight red shift is observed in the PVDF-HFP/PFDTMS infrared spectra in contrast with that of the pure PVDF-HFP membrane due to the electron-donating methyl groups contained in PFDTMS. These results demonstrate that neither the size nor the structure of the nanofibers have significantly changed after introducing PFDTMS into PVDF-HFP.

The PFDTMS possesses a lower surface energy than PVDF-HFP; consequently, it could serve as a surface energy regulator for the PVDF-HFP matrix by tuning its content. We note that the PFDTMS
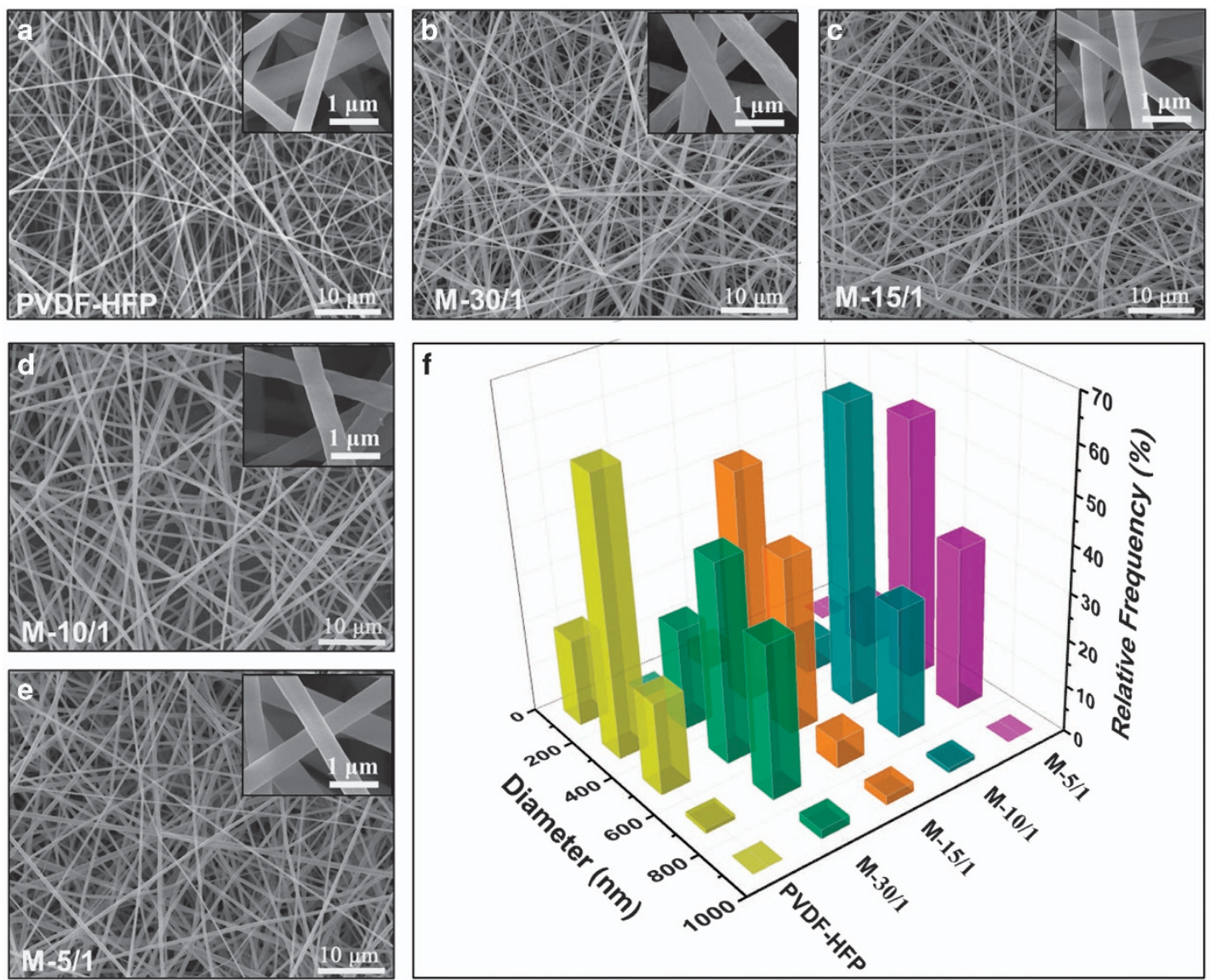

Figure 2 (a-e) SEM images of the uniform nanofibers: (a) pure PVDF-HFP; (b) M-30/1 with a weight ratio between PVDF-HFP and PFDTMS of 30:1; (c) $\mathrm{M}-15 / 1$; (d) $\mathrm{M}-10 / 1$; and (e) $\mathrm{M}-5 / 1$. The insets show high magnifications of the fibers, which demonstrate smooth surfaces without defects or folds. (f) Diameter distribution statistics of the PFDTMS-doped PVDF-HFP fibers, and different membranes have relatively similar fiber diameters. SEM, scanning electron microscopy. 
a

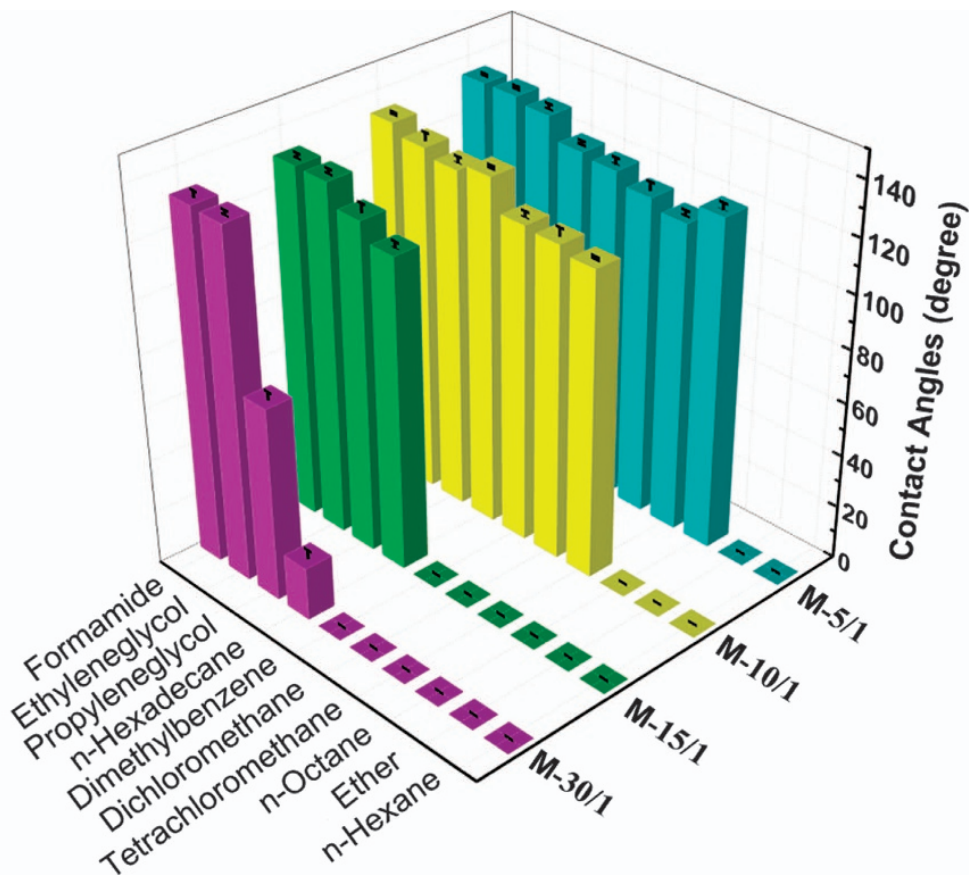

b

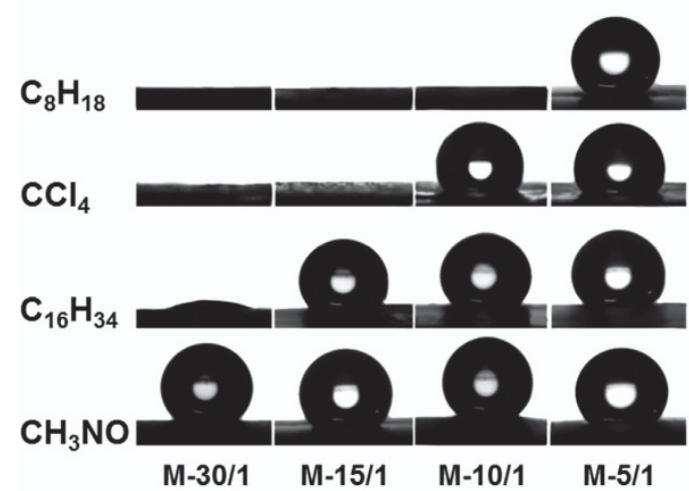

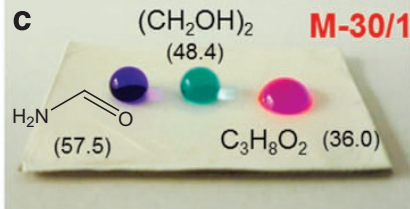

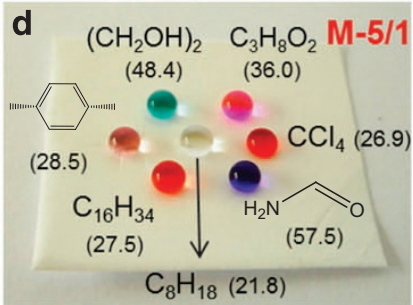

Figure 3 (a) CA values for various liquids on M-30/1, M-15/1, M-10/1 and M-5/1. The CAs of each liquid increase with increasing PFDTMS content. (b) CAs of n-octane, $\mathrm{CCl}_{4}$, $\mathrm{n}$-hexadecane and formamide droplets on the four membranes, showing that the trend of lyophobicity increases linearly with PFDTMSdoped content. (c) Photograph of formamide, ethylene glycol and propylene glycol droplets on the M-30/1 membrane with CA values of $132.4 \pm 1.4^{\circ}$,

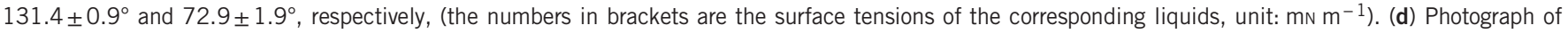
ethylene glycol, propylene glycol, dimethylbenzene, $\mathrm{n}$-octane, $\mathrm{CCl}_{4}$, hexadecane and formamide droplets on the $\mathrm{M}-5 / 1$ membrane with $\mathrm{CA}$ values of $135.4 \pm 0.5^{\circ}, 133.4 \pm 1.0^{\circ}, 124.0 \pm 1.3^{\circ}, 124.1 \pm 1.4^{\circ}, 116.3 \pm 1.0^{\circ}, 125.4 \pm 0.7^{\circ}$ and $135.3 \pm 0.3^{\circ}$, respectively.

content must be accurately controlled because it greatly affects the wettability of the fibrous membrane. Figure 3 shows the wettability of several organic liquids on as-prepared M-30/1, M-15/1, M-10/1 and $\mathrm{M}-5 / 1$. The figure indicates that the liquid repellency of the membranes improved as the PFDTMS content increased. From Young's equation: ${ }^{36-38} \cos \theta=\frac{\gamma_{\mathrm{sg}}-\gamma_{\mathrm{sl}}}{\gamma_{\mathrm{lg}}}$, where the liquid CA $(\theta)$ formed on a solid surface is closely associated with the interfacial tensions of the solid-gas $\left(\gamma_{\mathrm{sg}}\right)$, solid-liquid $\left(\gamma_{\mathrm{sl}}\right)$ and liquid-gas $\left(\gamma_{\mathrm{lg}}\right)$. The CAs of the liquids formed on the membrane surface decreased with decreasing liquid surface tension. As demonstrated in Figure 3a, the CAs of formamide $\left(57.5 \mathrm{mN} \mathrm{m}^{-1}\right)$, ethylene glycol $\left(48.4 \mathrm{mN} \mathrm{m}^{-1}\right)$ and propylene glycol $\left(36.0 \mathrm{mN} \mathrm{m}^{-1}\right)$ on $\mathrm{M}-30 / 1$ were $132.4 \pm 1.4^{\circ}$, $131.8 \pm 0.9^{\circ}$ and $72.9 \pm 1.9^{\circ}$, respectively. With further decreases in the liquid surface tension, the M-30/1 displayed lyophilicity to n-hexadecane $\left(27.5 \mathrm{mN} \mathrm{m}^{-1}\right)$ with a CA of $19.9 \pm 2.2^{\circ}$ and superlyophilicity to a liquid with a surface tension that was lower than n-hexadecane. Similar trends in liquid CA changes were also observed on M-15/1, M-10/1 and M-5/1, as shown in Figure 3a. The wetting liquids spread and permeate the membrane quickly, whereas the non-wetting liquids are retained above the membrane. On the basis of the obvious wetting difference, wetting liquids and non-wetting liquids are separated by the membrane. For one given liquid, the $\mathrm{CA}$ values on the four different membranes increased gradually from $M-30 / 1$ to $M-5 / 1$. A specified liquid might show different wetting behaviors on the four types of membranes due to the sequential decrease in surface energy caused by the increasing PFDTMS content. As illustrated in Figure $3 \mathrm{~b}$, the wetting behaviors of an n-octane $\left(21.8 \mathrm{mN} \mathrm{m}^{-1}\right)$ droplet changed from lyophilicity (on $\mathrm{M}-30 / 1, \mathrm{M}-15 / 1$ and $\mathrm{M}-10 / 1$ ) to lyophobicity (on M-5/1), that of the $\mathrm{CCl}_{4}\left(26.9 \mathrm{mN} \mathrm{m}^{-1}\right)$ droplet changed from lyophilicity 
(on M-30/1, M-15/1) to lyophobicity (on M-10/1, M-5/1) and of the n-hexadecane $\left(27.6 \mathrm{mN} \mathrm{m}^{-1}\right)$ droplet changed from lyophilicity (on M-30/1) to lyophobicity (on M-15/1, M-10/1 and M-5/1). It is noted that four membranes show superlyophobicity to formamide from first to last due to formamide's large surface tension, as illustrated. These results indicate that the liquid repellency of the membrane could be well controlled by tuning the PFDTMS content. The wetting behaviors of the nanofibrous membranes toward different liquid droplets are shown in Figure 3c. The CAs of formamide $\left(57.5 \mathrm{mN} \mathrm{m}^{-1}\right)$, ethylene glycol $\left(48.4 \mathrm{mN} \mathrm{m}^{-1}\right)$ and propylene glycol $\left(36.0 \mathrm{mN} \mathrm{m}^{-1}\right)$ are $132.4 \pm 1.4^{\circ}, 131.4 \pm 0.9^{\circ}$, and $72.9 \pm 1.9^{\circ}$ on M-30/1, respectively, which closely correspond to the surface tensions of the liquids. Figure $3 \mathrm{~d}$ reveals that formamide $\left(57.5 \mathrm{mN} \mathrm{m}^{-1}\right)$, ethylene glycol $\left(48.4 \mathrm{mN} \mathrm{m}^{-1}\right)$, propylene glycol $\left(36.0 \mathrm{mN} \mathrm{m}^{-1}\right)$, dimethylbenzene $\left(28.5 \mathrm{mN} \mathrm{m}^{-1}\right)$, hexadecane $\left(27.5 \mathrm{mN} \mathrm{m}^{-1}\right), \mathrm{CCl}_{4}$ $\left(26.9 \mathrm{mN} \mathrm{m}^{-1}\right)$ and $\mathrm{n}$-octane $\left(21.8 \mathrm{mN} \mathrm{m}^{-1}\right)$ droplets on $\mathrm{M}-5 / 1 \mathrm{had}$ CA values of $135.3 \pm 0.3^{\circ}, 135.4 \pm 0.5^{\circ}, 133.4 \pm 1.0^{\circ}, 124.0 \pm 1.3^{\circ}$, $125.4 \pm 0.7^{\circ}, 116.3 \pm 1.0^{\circ}$ and $124.1 \pm 1.4^{\circ}$, respectively. It is noted that $\mathrm{CCl}_{4}$ exhibited a slightly abnormal value and showed a smaller $\mathrm{CA}$ than that of $\mathrm{n}$-octane with lower surface tension. This result is due to the gravity deformation effect of $\mathrm{CCl}_{4}$ because its larger density $\left(1.595 \mathrm{~g} \mathrm{~cm}^{-3}\right.$ ) is greater than that of other light organic liquids (such as $\mathrm{n}$-octane of $0.692 \mathrm{~g} \mathrm{~cm}^{-3}$, hexadecane of $0.773 \mathrm{~g} \mathrm{~cm}^{-3}$ ). These results demonstrate that M-5/1 presents excellent repellency toward a wider range of organic liquids. To further prove the relationship between the proportion of PFDTMS and the liquid-repellent properties, the silicon element content was determined as a reference to calculate the fluorine element content via energy dispersive spectroscopy (Supplementary Figure S4). The results demonstrate the increasing silicon content from $M-30 / 1$ to $M-5 / 1$, which is in accordance with the distribution trend in our experimental design.

The results show that two liquids with a certain difference in surface tension can exhibit opposite wetting performances on a certain nanofibrous membrane of appropriate surface energy, and a liquid mixture with wetting differences could be separated by that membrane. As mentioned previously, the PVDF-HFP electrospun membrane displays the superhydrophobic property itself and can be used in oil/water separation but not for separation of low surface tension organic liquid mixtures. As shown in Figures $4 \mathrm{a}$ and $\mathrm{b}$, when we poured an oil mixture of propylene glycol $\left(36.0 \mathrm{mN} \mathrm{m}^{-1}\right.$, colorless) and $\mathrm{CCl}_{4}\left(26.9 \mathrm{mN} \mathrm{m}^{-1}\right.$, red) on the pure PVDF-HFP membrane, these two liquids passed through the PVDF-HFP membrane spontaneously. As a comparison, $\mathrm{CCl}_{4}$ could easily pass through M-10/1, whereas propylene glycol was completely intercepted on the membrane. In other words, the low surface tension organic liquids of propylene glycol and $\mathrm{CCl}_{4}$ could be successfully separated by M-10/1 (Supplementary Video 2). This result demonstrates that controllable separation of organic liquid mixtures can be feasibly achieved by regulating the membrane surface energy. Several examples of separation processes and the results of organic liquid mixtures tested on our PFDTMS-doped PVDF-HFP membranes are shown in Figures $4 \mathrm{c}-\mathrm{h}$. The mixture of formamide (blue) and $\mathrm{CCl}_{4}$ (red) could be separated by $\mathrm{M}-15 / 1$ (Figures $4 \mathrm{c}-\mathrm{d}$ ). In this case, the $\mathrm{CCl}_{4}$ with lower surface tension penetrated the membrane immediately while non-wetting formamide was intercepted on the membrane (Supplementary Video 3). The separation process via M-10/1 for a mixture of wetting dimethylbenzene with lower density (red) and non-wetting ethylene glycol (green) is shown in Figures 4e-f. Figures $4 \mathrm{~g}-\mathrm{h}$ shows the separation result of wetting petroleum ether (colorless) and non-wetting propylene glycol (rose pink). The above cases offer a few examples of separation, but in fact, a wide range of separations is possible for the membrane with tunable lyophobicity.

A schematic representation of the selective separation mechanism is illustrated in Figures $5 \mathrm{a}$ and $\mathrm{b}$. When a wettable liquid contacts the membrane, it spreads instantly on the membrane under the action of the capillary force. The wetting liquid permeates the film spontaneously. In contrast, the lyophobic membrane creates a repellency force on the non-wettable liquid, and the non-wettable liquid is blocked by the membrane unless the gravity pressure $\left(P_{\text {breakthrough }}\right)$ is greater than the repellency force. ${ }^{39}$ For a membrane composed of nanofibers, $R$ is the fiber radius, and $2 D$ is the space between two adjacent fibers. The breakthrough pressure of a non-wetting liquid required to pass through a membrane completely
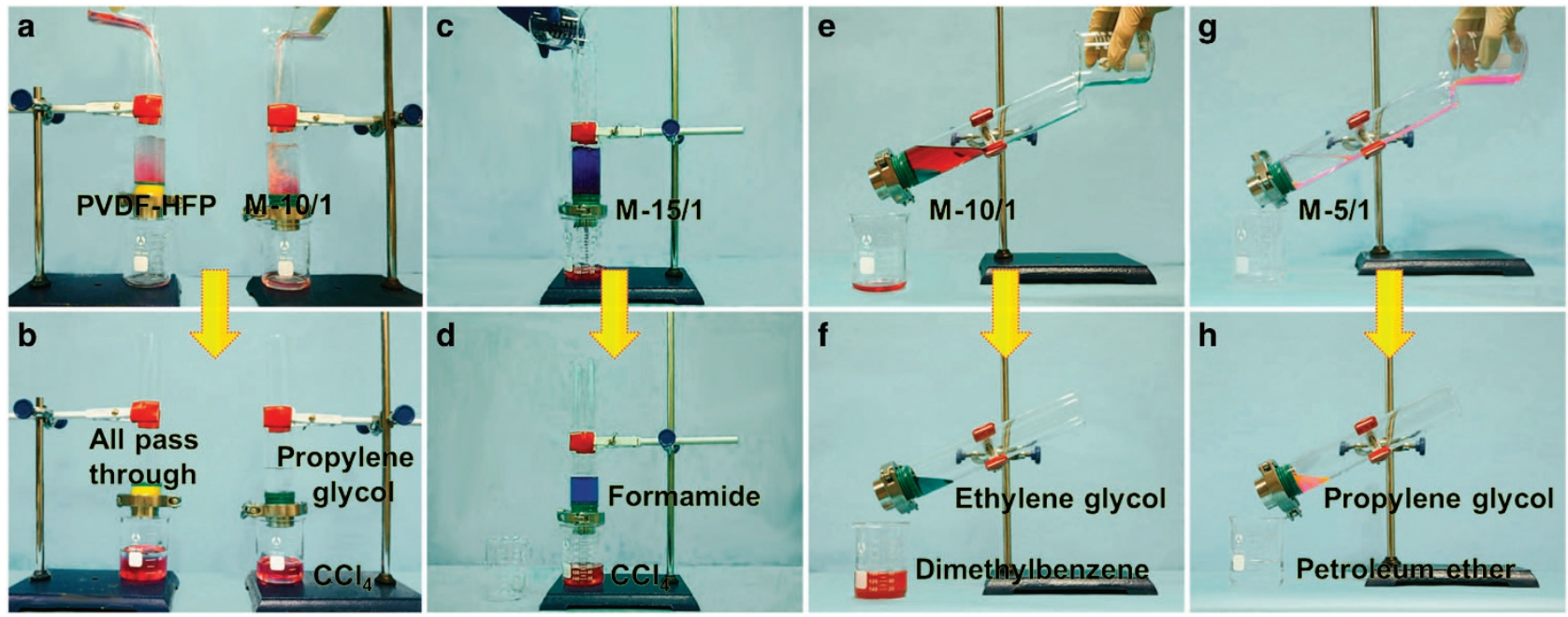

Figure 4 Several examples of organic liquid separation based on the PFDTMS/PVDF-HFP nanofibrous membrane. (a, b) The pure PVDF-HFP fibrous membrane cannot be used to separate an oil mixture containing propylene glycol and $\mathrm{CCl}_{4}$ because both liquids will pass through the PVDF-HFP membrane, but the M-10/1 membrane with lower surface energy can separate these two liquids. The separation process and results for (c, d) formamide and $\mathrm{CCl}_{4}$ mixture on $\mathrm{M}-15 / 1$, (e, f) ethylene glycol and dimethylbenzene mixture on $\mathrm{M}-10 / 1,(\mathbf{g}, \mathbf{h}$ ) propylene glycol and petroleum ether mixture on $\mathrm{M}-5 / 1$. These results demonstrate that various organic liquids are effectively separated. 
a
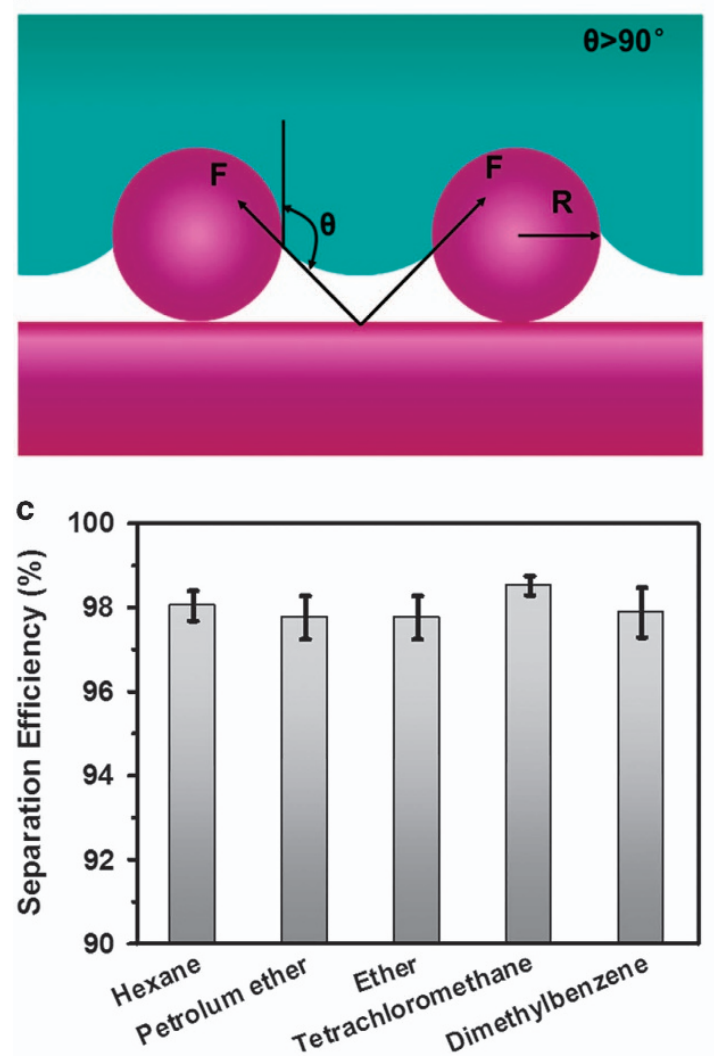

b

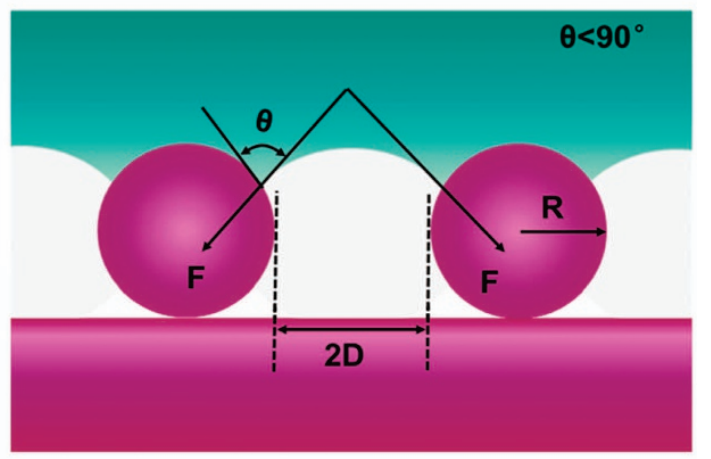

d

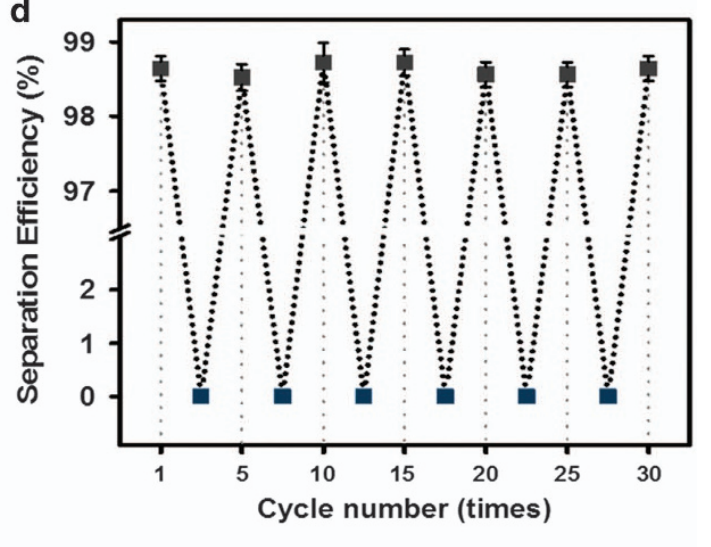

Figure 5 Solid-liquid contact modes of (a) non-wetting liquids and (b) wetting liquids on the nanofibrous membrane. $\mathrm{R}$ represents the single-membrane fiber radius, $2 \mathrm{D}$ is the space between two adjacent fibers and $\mathrm{F}$ indicates the repellent force of the fibrous membrane acting on the liquid. (c) The separation efficiencies of $\mathrm{M}-15 / 1$ toward liquid mixtures of hexane, petroleum ether, ether, $\mathrm{CCl}_{4}$ and dimethylbenzene with formamide were $98.0 \pm 0.4 \%, 97.8 \pm 0.5 \%$, $97.8 \pm 0.5 \%, 98.5 \pm 0.2 \%$ and $97.9 \pm 0.6 \%$, respectively. (d) Separation efficiency for liquid mixtures of $\mathrm{CCl} 4$ and formamide by $\mathrm{M}_{-15 / 1}$ after repeated recycling. The recycling separation efficiencies corresponding to cycle numbers 1, 5, 10, 15, 20, 25 and 30 were still >98.5\%. $2 \mathrm{D}$, two-dimensional.

infiltrated by another wetting liquid can be written as: ${ }^{39}$

$$
P_{\text {breakthrough }}=\frac{2 R \gamma_{12}}{D^{2}} \frac{1-\cos \left(\theta^{\prime}\right)}{1+2(R / D) \sin \left(\theta^{\prime}\right)}
$$

where $\gamma_{12}$ represents the interfacial tension between the permeable liquid and the impermeable liquid, and $\theta^{\prime}$ is the CA of the non-wetting liquid on the membrane surface. The non-wetting liquid will not penetrate the membranes unless the liquid pressure $P_{\text {liquid }}>P_{\text {breakthrough. }}$ On the basis of this principle, the wetting liquid and non-wetting liquid can be separated on our membranes under the condition of $P_{\text {liquid }}<P_{\text {breakthrough. In addition, the separation efficiency }}$ is another important factor that must be considered for a separation membrane and can be calculated by equation (2):

$$
R(\%)=\left(\frac{V_{\mathrm{c}}+V_{\mathrm{e}}}{V_{\mathrm{o}}}\right) \times 100 \%
$$

where $V_{\mathrm{c}}$ and $V_{\mathrm{e}}$ are the collected and evaporated volumes of the wetting liquid after separation and in the process of separation, and $V_{\mathrm{o}}$ is the original wetting liquid volume before separation. Taking the M-15/1 membrane for example, the separation efficiency results with mixtures of formamide versus other liquids that could be separated are presented in Figure 5c. The separation efficiencies of M-15/1 for mixtures of formamide and n-hexane, petroleum ether, ether, $\mathrm{CCl}_{4}$, dimethylbenzene are $98.0 \pm 0.5 \%, 97.8 \pm 0.5 \%, 97.8 \pm 0.5 \%$, $98.5 \pm 0.2 \%$ and $97.9 \pm 0.6 \%$, respectively. Compared with brittle inorganic oxide membranes, ${ }^{40}$ a notable advantage of such a polymeric membrane is that it possesses good flexibility and high strength for practical applications. The stress value of $\mathrm{M}-15 / 1$ reaches as high as $5.41 \mathrm{MPa}$ (Supplementary Figure S10), suggesting the excellent robustness of the membranes. The good flexibility, high mechanical property and good chemical durability (Supplementary Figure S5-S9) ensure the suitability of these membranes for large-area applicability and promising recyclability in mixed organic liquids separation. For example, even after recycling separation of formamide and $\mathrm{CCl}_{4}$ for more than 30 repetitions, the M-15/1 membrane still exhibited good chemical and structural durability with a separation efficiency of greater than $98.5 \%$, as shown in Figure 5 d.

The separable liquid couples of four membranes are summarized as tables (Table 1 and Supplementary Table S1-S3). For example, a portion of the separation results via the four membranes for non-permeable liquids versus other permeable liquids are shown in the simplified Table 1 (additional separation results are collected in Supplementary Table S1-S3). In this work, the fluorine content is the key factor that can enhance the membrane lyophobicity. The ladder-shaped separation results were observed separated results of the ladder shape were shown because of the decreasing tendency of the membrane surface energy from left to right as the fluorine content increases. In addition, the as-prepared membranes can also be applied in oil/water separation (Supplementary Table S4). 
Table 1 Components of separation results for liquid mixtures using four membranes

\begin{tabular}{|c|c|c|c|c|}
\hline \multirow[b]{2}{*}{ Liquid couples } & \multicolumn{4}{|c|}{ Separation results } \\
\hline & \multicolumn{4}{|c|}{ Membranes } \\
\hline & $M-30 / 1$ & $M-15 / 1$ & $M-10 / 1$ & $M-5 / 1$ \\
\hline \multicolumn{5}{|l|}{$F A$} \\
\hline n-Hexadecane & $\sqrt{ }$ & $x$ & $\times$ & $x$ \\
\hline Dodecane & $\sqrt{ }$ & $x$ & $x$ & $x$ \\
\hline Benzene & $\sqrt{ }$ & $\sqrt{ }$ & $\sqrt{ }$ & $x$ \\
\hline Dichloromethane & $\sqrt{ }$ & $\sqrt{ }$ & $\sqrt{ }$ & $x$ \\
\hline n-Decane & $\sqrt{ }$ & $\sqrt{ }$ & $\sqrt{ }$ & $\sqrt{ }$ \\
\hline Ether & $\sqrt{ }$ & $\sqrt{ }$ & $\sqrt{ }$ & $\sqrt{ }$ \\
\hline \multicolumn{5}{|l|}{$E G$} \\
\hline n-Hexadecane & $\sqrt{ }$ & $x$ & $x$ & $x$ \\
\hline Dodecane & $\sqrt{ }$ & $x$ & $x$ & $x$ \\
\hline Methylbenzene & $\sqrt{ }$ & $\sqrt{ }$ & $\sqrt{ }$ & $\times$ \\
\hline Trichloromethane & $\sqrt{ }$ & $\sqrt{ }$ & $\sqrt{ }$ & $\times$ \\
\hline Cyclopentane & $\sqrt{ }$ & $\sqrt{ }$ & $\sqrt{ }$ & $\sqrt{ }$ \\
\hline n-Hexane & $\sqrt{ }$ & $\sqrt{ }$ & $\sqrt{ }$ & $\sqrt{ }$ \\
\hline \multicolumn{5}{|l|}{$P G$} \\
\hline Dimethylbenzene & $x$ & $x$ & $\sqrt{ }$ & $x$ \\
\hline Tetrachloromethane & $x$ & $x$ & $\sqrt{ }$ & $x$ \\
\hline n-Octane & $\times$ & $\times$ & $\sqrt{ }$ & $\sqrt{ }$ \\
\hline n-Heptane & $\times$ & $\times$ & $\sqrt{ }$ & $\sqrt{ }$ \\
\hline
\end{tabular}

'The ' $\sqrt{ }$ ', symbol indicates that the liquid mixtures can be separated and the ' $x$ ' indicates that the mixtures cannot be separated. FA, EG and PG represent the liquids of formamide, ethylene glycol and propylene glycol, respectively.

\section{CONCLUSION}

In summary, we have proposed a simple and effective approach for fabrication of PFDTMS-doped PVDF-HFP composite nanofibrous membranes with easily tunable wettability that can separate various organic liquids with a small surface tension difference in a highly efficient manner. The membranes show good flexibility and excellent mechanical performance, which give them excellent recycling applicability for real and complex industry domains. Although only four types of membranes were prepared in the current work, the facile and programmable design can create additional membranes with subdivided surface energies according to actual separation requirements. This strategy will make a significant contribution to addressing multiphase organic liquid and chemical products separation, oil spill accidents and other environmental problems.

\section{CONFLICT OF INTEREST}

The authors declare no conflict of interest.

\section{ACKNOWLEDGEMENTS}

We are grateful for the financial support from the National Natural Science Foundation of China (21433012, 21134003, 21374001, 21222309), the 863 Program (2013AA032203), the 973 Program (2012CB933200), the Fundamental Research Funds for the Central Universities and the China Scholarship Council (201406025059, 201506025110).

1 Kajitvichyanukul, P., Hung, Y.-T., Wang, L. In Advanced Physicochemical Treatment Processes. (eds Wang, L., Hung, Y.-T. \& Shammas, N.) (Humana Press, Totowa, NJ, USA, 2006)
2 Lei, Z. G., Li, C. Y. \& Chen, B. H. Extractive distillation: a review. Sep. Purif. Rev. 32, 121-213 (2003).

3 Feng, L., Zhang, Z., Mai, Z., Ma, Y., Liu, B., Jiang, L. \& Zhu, D. A super-hydrophobic and super-oleophilic coating mesh film for the separation of oil and water. Angew Chem. Int. Ed. Engl. 43, 2012-2014 (2004).

4 Yuan, J., Liu, X., Akbulut, O., Hu, J., Suib, S. L., Kong, J. \& Stellacci, F. Superwetting nanowire membranes for selective absorption. Nat. Nanotechnol. 3, 332-336 (2008).

5 Gui, X., Wei, J., Wang, K., Cao, A., Zhu, H., Jia, Y., Shu, Q. \& Wu, D. Carbon nanotube sponges. Adv. Mater. 22, 617-621 (2010).

6 Zhu, Q. \& Pan, Q. Mussel-inspired direct immobilization of nanoparticles and application for oil-water separation. ACS Nano 8, 1402-1409 (2014).

7 Wang, C., Yao, T., Wu, J., Ma, C., Fan, Z., Wang, Z., Cheng, Y., Lin, Q. \& Yang, B. Facile approach in fabricating superhydrophobic and superoleophilic surface for water and oil mixture separation. ACS Appl. Mater. Interfaces 1, 2613-2617 (2009).

8 Calcagnile, P., Fragouli, D., Bayer, I. S., Anyfantis, G. C., Martiradonna, L., Cozzoli, P. D., Cingolani, R. \& Athanassiou, A. Magnetically driven floating foams for the removal of oil contaminants from water. ACS Nano 6, 5413-5419 (2012).

9 Zhang, L., Zhong, Y., Cha, D. \& Wang, P. A self-cleaning underwater superoleophobic mesh for oil-water separation. Sci. Rep. 3, 2326 (2013).

10 Wang, B., Liang, W., Guo, Z. \& Liu, W. Biomimetic super-lyophobic and super-lyophilic materials applied for oil/water separation: a new strategy beyond nature. Chem. Soc. Rev. 44, 336-361 (2015).

$11 \mathrm{Chu}$, Z., Feng, Y. \& Seeger, S. Oil/water separation with selective superantiwetting/ superwetting surface materials. Angew Chem. Int. Ed. Engl. 54, 2328-2338 (2015).

12 Xue, Z., Cao, Y., Liu, N., Feng, L. \& Jiang, L. Special wettable materials for oil/water separation. J. Mater. Chem. A 2, 2445-2460 (2014).

13 Darmanin, T. \& Guittard, F. Wettability of conducting polymers: from superhydrophilicity to superoleophobicity. Prog. Polym. Sci. 39, 656-682 (2014).

14 Brown, P. S. \& Bhushan, B. Mechanically durable, superoleophobic coatings prepared by layer-by-layer technique for anti-smudge and oil-water separation. Sci. Rep. 5, 8701 (2015).

15 Liu, M., Wang, S., Wei, Z., Song, Y. \& Jiang, L. Bioinspired design of a superoleophobic and low adhesive water/solid interface. Adv. Mater. 21, 665-669 (2009).

16 Shi, F., Wang, Z. \& Zhang, X. Combining a layer-by-layer assembling technique with electrochemical deposition of gold aggregates to mimic the legs of water striders. Adv. Mater. 17, 1005-1009 (2005).

17 Crick, C. R., Gibbins, J. A. \& Parkin, I. P. Superhydrophobic polymer-coated copper-mesh; membranes for highly efficient oil-water separation. J. Mater. Chem. A 1, 5943-5948 (2013).

18 Zhang, J. \& Seeger, S. Polyester materials with superwetting silicone nanofilaments for oil/water separation and selective oil absorption. Adv. Funct. Mater. 21, 4699-4704 (2011).

19 Zhang, L., Zhang, Z. \& Wang, P. Smart surfaces with switchable superoleophilicity and superoleophobicity in aqueous media: toward controllable oil/water separation. NPG Asia Mater. 4, e8 (2012).

20 Ge, D., Yang, L., Wang, C., Lee, E., Zhang, Y. \& Yang, S. A multi-functional oil-water separator from a selectively pre-wetted superamphiphobic paper. Chem. Commun. 51, 6149-6152 (2015).

21 Zhang, F., Zhang, W. B., Shi, Z., Wang, D., Jin, J. \& Jiang, L. Nanowire-haired inorganic membranes with superhydrophilicity and underwater ultralow adhesive superoleophobicity for high-efficiency oil/water separation. Adv. Mater. 25, 4192-4198 (2013).

22 Zhang, J., Wu, L., Zhang, Y. \& Wang, A. Mussel and fish scale-inspired underwater superoleophobic kapok membranes for continuous and simultaneous removal of insoluble oils and soluble dyes in water. J. Mater. Chem. A 3, 18475-18482 (2015).

23 Xie, Q., Xu, J., Feng, L., Jiang, L., Tang, W., Luo, X. \& Han, C. C. Facile creation of a super-amphiphobic coating surface with bionic microstructure. Adv. Mater. 16, 302-305 (2004).

24 Li, H., Wang, X., Song, Y., Liu, Y., Li, Q., Jiang, L. \& Zhu, D. Super-“amphiphobic” aligned carbon nanotube films. Angew Chem. Int. Ed. Engl. 40, 1743-1746 (2001).

25 Bellanger, H., Darmanin, T., Taffin de Givenchy, E. \& Guittard, F. Chemical and physical pathways for the preparation of superoleophobic surfaces and related wetting theories. Chem. Rev. 114, 2694-2716 (2014).

26 Darmanin, T. \& Guittard, F. Molecular design of conductive polymers to modulate superoleophobic properties. J. Am. Chem. Soc. 131, 7928-7933 (2009).

27 Lu, Y., Song, J., Liu, X., Xu, W., Xing, Y. \& Wei, Z. Preparation of superoleophobic and superhydrophobic titanium surfaces via an environmentally friendly electrochemical etching method. ACS Sustain. Chem. Eng. 1, 102-109 (2013).

28 Deng, X., Mammen, L., Butt, H.-J. \& Vollmer, D. Candle soot as a template for a transparent robust superamphiphobic coating. Science 335, 67-70 (2012).

29 Zhou, H., Wang, H., Niu, H., Gestos, A. \& Lin, T. Robust, self-healing superamphiphobic fabrics prepared by two-step coating of fluoro-containing polymer, fluoroalkyl silane, and modified silica nanoparticles. Adv. Funct. Mater. 23, 1664-1670 (2013).

30 Wang, L., Zhao, Y., Tian, Y. \& Jiang, L. A general strategy for the separation of immiscible organic liquids by manipulating the surface tensions of nanofibrous membranes. Angew Chem. Int. Ed. Engl. 54, 14732-14737 (2015).

31 Shi, L., Wang, R., Cao, Y., Liang, D. T. \& Tay, J. H. Effect of additives on the fabrication of poly(vinylidene fluoride-co-hexafluropropylene) (PVDF-HFP) asymmetric microporous hollow fiber membranes. J. Membr. Sci. 315, 195-204 (2008). 
32 Nuraje, N., Khan, W. S., Lei, Y., Ceylan, M. \& Asmatulu, R. Superhydrophobic electrospun nanofibers. J. Mater. Chem. A 1, 1929-1946 (2013).

$33 \mathrm{Wu}$, J., Wang, N., Zhao, Y. \& Jiang, L. Electrospinning of multilevel structured functional micro-/nanofibers and their applications. J. Mater. Chem. A 1, 7290-7305 (2013).

$34 \mathrm{Wu}$, J., Wang, N., Zhao, Y. \& Jiang, L. Simple synthesis of smart magnetically driven fibrous films for remote controllable oil removal. Nanoscale 7, 2625-2632 (2015).

$35 \mathrm{Si}$, Y., Yu, J., Tang, X., Ge, J. \& Ding, B. Ultralight nanofibre-assembled cellular aerogels with superelasticity and multifunctionality. Nat. Commun. 5, 5802 (2014).

36 Parker, A. R. \& Lawrence, C. R. Water capture by a desert beetle. Nature 414, 33-34 (2001).

37 Cassie, A. B. D. \& Baxter, S. Wettability of porous surfaces. J. Chem. Soc. Faraday Trans. 40, 546-551 (1944).

38 Young, T. An essay on the cohesion of fluids. Philos. Trans. R. Soc. Lond. 95, 65-87 (1805).

39 Kota, A. K., Kwon, G., Choi, W., Mabry, J. M. \& Tuteja, A. Hygro-responsive membranes for effective oil-water separation. Nat. Commun. 3, 1025 (2012).
40 Wang, X., Ding, B., Yu, J. \& Wang, M. Engineering biomimetic superhydrophobic surfaces of electrospun nanomaterials. Nano Today 6, 510-530 (2011).

(c) (i) This work is licensed under a Creative Commons Attribution 4.0 International License. The images or other third party material in this article are included in the article's Creative Commons license, unless indicated otherwise in the credit line; if the material is not included under the Creative Commons license, users will need to obtain permission from the license holder to reproduce the material. To view a copy of this license, visit http:// creativecommons.org/licenses/by/4.0/

(C) The Author(s) 2016

Supplementary Information accompanies the paper on the NPG Asia Materials website (http://www.nature.com/am) 